\title{
Clinical Psychologists' Firearm Risk Management Perceptions and Practices
}

\author{
Andrea Traylor $\cdot$ James H. Price $\cdot$ \\ Susan K. Telljohann · Keith King • \\ Amy Thompson
}

Published online: 22 January 2010

(C) The Author(s) 2010. This article is published with open access at Springerlink.com

\begin{abstract}
The purpose of this study was to investigate the current perceptions and practices of discussing firearm risk management with patients diagnosed with selected mental health problems. A three-wave survey was mailed to a national random sample of clinical psychologists and 339 responded $(62 \%)$. The majority $(78.5 \%)$ believed firearm safety issues were greater among those with mental health problems. However, the majority of clinical psychologists did not have a routine system for identifying patients with access to firearms $(78.2 \%)$. Additionally, the majority (78.8\%) reported they did not routinely chart or keep a record of whether patients owned or had access to firearms. About one-half $(51.6 \%)$ of the clinical psychologists reported they would initiate firearm safety counseling if the patients were assessed as at risk for self-harm or harm to others. Almost half $(46 \%)$ of clinical psychologists
\end{abstract}

A. Traylor ( $\square)$

Family Studies \& Social Work, Miami University,

McGuffey Hall 110 H, Oxford, OH 45056, USA

e-mail: kinnisar@muohio.edu

J. H. Price · S. K. Telljohann - A. Thompson

Department of Health and Rehabilitative Services,

The University of Toledo, 2801 W. Bancroft Mail Stop 119,

Toledo, OH 43606, USA

e-mail: jprice@utnet.utoledo.edu

S. K. Telljohann

e-mail: stelljo@utnet.utoledo.edu

A. Thompson

e-mail: athomps16@utnet.utoledo.edu

K. King

Health Promotion \& Education, University of Cincinnati,

TEACHERS 526E, PO Box 210068, Cincinnati,

OH 45221, USA

e-mail: keith.king@uc.edu reported not receiving any information on firearm safety issues. Thus, the findings of this study suggest that a more formal role regarding anticipatory guidance on firearms is needed in the professional training of clinical psychologists.

Keywords Suicide - Firearms · Risk - Assessment . Homicide $\cdot$ Mental health

\section{Introduction}

In 2003, firearms were responsible for 30,136 deaths [1]. The majority of these deaths were suicides, accounting for $16,907(57 \%)$ of these deaths [1]. Suicide was the 11th leading cause of death in the United States [2,3]. Firearms are the most common method (57\%) of completed suicides. Firearms are used three times more often than hanging, which is the second most common method of completed suicides [2]. A positive association has been demonstrated between suicide and firearm ownership, as well as homicide and firearm ownership [4-6]. Firearms are used in $67 \%$ of homicides [7]. Storing firearms locked and unloaded decreases the risk of firearm suicide [8]. However, keeping a firearm in the home regardless of storage method increases the risk of suicide and homicide [9].

Several factors are linked to increased suicide rates. These include gender, availability of firearms in the home, carrying weapons and psychiatric disorders [10-15]. A firearm in the home increased the risk of completed suicide by firearms among both sexes (odds ratio, $\mathrm{OR}=31.1$ ) [9].

Depression, bipolar disorder, schizophrenia, personality disorders, and affective disorders are associated with repeated suicide attempts and suicide ideation $[11,12,16$, 17]. Schizophrenic patients have a significantly greater risk 
of suicide than the general population $(\mathrm{OR}=9.9)$ [18]. Patients with mental health disorders and co-morbid alcoholism are at greatest risk of suicide [19]. Alcohol consumption increases the risk of dying by suicide for men $(\mathrm{OR}=3.18)$ and women $(\mathrm{OR}=2.81)$ [20]. A variety of studies have explored various groups of physicians' and their perceived roles in reducing firearm injuries and premature mortality in patients [21, 22]. Most of these studies of physicians focused on primary care providers, including family physicians, internists, and pediatricians [21, 23-27]. A recent national study of psychiatrists and their practices and perceptions regarding anticipatory guidance on firearms found psychiatrists perceived firearm safety issues as especially important, yet only $27 \%$ had a routine system for identifying patients who owned firearms [28]. In addition, $45 \%$ had never thought seriously about discussing firearm safety issues with patients.

The American Psychological Association and the International Association for Suicide Prevention both have published guidelines on suicide risk assessment [29, 30]. However, no published studies could be found regarding firearm counseling practices of clinical psychologists. This is especially noteworthy since approximately $90 \%$ of suicides are among individuals with a mental health problem [15]. In a previous study on preventive medical services, only $6 \%$ of psychiatric patients reported being asked about firearm ownership [31]. A study of counselors found that $23 \%$ had a patient under their care commit suicide [32]. Restriction of access to firearms, especially during a mental crisis, could decrease the number of firearm related suicides [13-15]. A recent review of suicide prevention strategies for physicians concluded there were only two solutions that had substantial scientific merit in the literature for reducing suicides: (1) physician education in depression recognition and treatment, and (2) restricting access to lethal means (namely firearms) [33].

During patient treatment, clinical psychologists are in a unique position to counsel patients on firearm safety and could decrease the likelihood of a firearm suicide by helping limit access to firearms during critical periods. In essence, it would seem that both psychologists and psychiatrists have a "duty to treat" patients regarding the risks of firearms, whether stored at home or carried on them. Preliminary evidence indicates that firearm risk management with mental health patients can help reduce the potential for firearm violence [34].

To date, no studies have been published regarding firearm counseling practices of clinical psychologists. Yet, restriction of access to firearms, especially during a mental crisis, could decrease the number of firearm related suicides and homicides [13-15].

The purpose of this study was to investigate clinical psychologists' firearm risk management activities with patients. More specifically, answers to the following questions were sought: Do the majority of clinical psychologists discuss firearm safety issues with clients? Do clinical psychologists perceive patients with mental health problems to be at a greater risk from firearm injury/death than the general population and if so, which mental health problems create greater risk? What topics do clinical psychologists cover during firearm safety counseling? What are the barriers perceived by clinical psychologists to firearm safety counseling? What are clinical psychologists' efficacy and outcome expectations in applying the "5As" (Ask, Advise, Assess, Assist and Arrange) in firearm safety counseling? Where have clinical psychologists obtained the majority of their training on anticipatory guidance on firearms?

\section{Methods}

\section{Subjects}

A national random sample of 600 clinical psychologists in the United States was obtained in 2006 from the American Psychological Association (APA) membership roster $(n=155,000)$. A power analysis was conducted to determine the sample size needed of clinical psychologists. Sample size was determined based on an alpha of .05, effect size at $20 \%$ with $80 \%$ power to minimize Type I error [35]. The suggested sample size was 323 based on a $70 / 30$ split in firearm safety counseling practices with a $5 \%$ margin of error. An a priori power analysis demonstrated that this sample size should be adequate to generalize the results to the total APA population of clinical psychologists. However, considering the chance of nonresponses, 600 surveys were mailed to clinical psychologists with the intention of obtaining greater than a $50 \%$ return rate.

\section{Instrument Development}

A four-page, 18 item survey was constructed based on the literature on firearms and professional anticipatory guidance on firearm safety. The first question described potential circumstances in which clinical psychologists would discuss firearm safety issues with patients. The next series of questions examined firearm safety discussions between patients with mental health problems and their psychologists. Items included the percentage of patients counseled with selected mental disorders (alcoholism/other substance abuse, anxiety disorder, bipolar disorder, borderline personality disorder, major depression, panic disorder, PTSD, schizophrenia, social phobia, suicidal patients, and other disorders). The next section identified nine potential barriers to discussing firearm safety with 
patients and a three part question on patient characteristics (sex, race/ethnicity and age). The psychologists were also asked if patient characteristics affected the probability of counseling patients regarding firearm safety issues. This was measured on a scale of one to five, with one being no difference in counseling and five being greatly increased probability of counseling.

The next section asked about efficacy expectations and outcome expectations (self-efficacy) subscales based on the $5 A$ 's regarding firearms in the home [36]. This was measured by five response options with a Likert-type scale ranging from not confident at all to highly confident (efficacy expectations). The 5A's included: asking clients about the presence of a handgun in the home, advising the patient to remove the handgun from immediate home access, assessing the willingness of the patient to remove the handgun within the next 30 days, assisting the patient in selecting other home safety techniques and what to do with the handgun, and arranging follow-up contact within 4 weeks to assess removal and the need for more assistance [37]. This was followed by outcome expectations of the 5A's strategy, that included: fewer accidental firearm injuries and death to patients and/or their families, reduction in the number of suicides in patients and/or their families, reduction in the number of homicides in patients and/or their families, and reduction in the number of patient's homes with firearms. The last question in this section asked clinical psychologists where they received the majority of their information regarding anticipatory guidance on firearms. The final section of the survey identified participants demographic characteristics.

Face validity for the items was established by constructing the items after reviewing the current literature in the area of health professionals firearm risk management and mental illness. Content validity of the instrument was established by national expert review $(n=4)$ of the instrument. Experts were those published in the areas of firearms, mental illness and/or survey research. Minor wording changes to some items were suggested by reviewers and were incorporated into the final instrument.

The stability reliability of the instrument was established using a convenience sample of clinical psychologists $(n=10)$ as a pilot test, and Pearson product moment correlation coefficients for the subscales ranged from .68 to 1.0. The subscales were assessed, using final survey returns, to establish internal stability reliability (Cronbach alpha). The subscale results ranged from a low of .89 for mental health to a high of .97 of barriers to firearm safety counseling.

\section{Procedures}

A three-wave mailing was utilized to maximize the response rate. The first wave included a personalized letter, hand signed in contrasting ink. Personalized letters increase response rates for mail surveys $(\mathrm{OR}=1.16)$ [38]. Also included was a copy of the survey on pastel colored paper, a $\$ 1.00$ bill, and a prestamped self-addressed envelope. Monetary incentives also increase the response rate $(\mathrm{OR}=2.02)$ [38].

The second wave included a hand signed cover letter, survey, and a self-addressed stamped return envelope. Edwards et al. found that sending a replacement survey to non-respondents increased return rates [38]. The second was sent 2 weeks after the first wave. Respondents were reminded to disregard the second mailing if they had previously completed the survey [39].

The third wave was a postcard of similar color as the questionnaire, mailed 4 weeks after the initial mailing, or 2 weeks after the second mailing. The purpose of the postcard was to stimulate responses from the non-respondents [39, 40]. This reduced nonrespondent bias and increased the external validity of the results.

\section{Data Analysis}

After the three wave mailing was complete, survey data was entered into SPSS. The appropriate descriptive statistics were analyzed to describe the findings. Statistical analysis included chi-square tests.

\section{Results}

Demographic and Background Characteristics

Fifty-two surveys were returned not completed for a variety of reasons (e.g., moved, retired, deceased etc.). Of the possible 548 survey respondents, 339 were returned for a response rate of $62.0 \%$ (339/548), which was sufficient for external validity of the findings. Of the 339 psychologists, the majority, 206 (60.8\%) were male. One-half of the clinical psychologists were between the ages of 50 and 59 years $(50.1 \%)$, while $29.2 \%$ of the clinical psychologists were between the ages of 60 and 69 years. The vast majority of the clinical psychologists were Caucasian (94.4\%). Approximately one-quarter $(n=85)$ of responding clinical psychologists reported owning a firearm. Of these, 48 ( $14.2 \%$ of the total sample) owned a handgun, and 62 (18.3\% of the total sample) owned a long-gun. Sixtyeight of the firearm owners reported storing their firearms in their home ( $20.1 \%$ of the total sample).

Anticipatory Guidance of Firearm Safety

The majority of respondents perceived firearm safety issues as greater $(78.5 \%)$ in those with mental health problems 
compared to the general population. However, the majority (78.2\%) did not have a routine system for identifying patients with access to firearms. Additionally, the vast majority $(78.8 \%)$ of clinical psychologists reported they did not routinely chart or keep a record of whether repeat adult patients owned or had access to firearms. About onehalf of the clinical psychologists $(51.6 \%)$ reported they currently initiated anticipatory guidance on firearm safety if the patients were assessed as at risk for self-harm or harm to others. Almost one-fourth (24.5\%) reported they had not seriously thought about discussing firearm safety with their patients. Clinical psychologists were asked if certain characteristics (e.g., male, racial/ethnic minorities, and low socioeconomic status) affected their probability of providing firearm safety counseling. Over half $(52.2 \%)$ of the clinical psychologists felt patients being male did not increase the probability of them providing firearm safety counseling. Four out of $5(80.5 \%)$ clinical psychologists felt patients being racial/ethnic minorities or of low socioeconomic status (79\%) did not increase the likelihood they would provide firearm safety counseling. The probability that clinical psychologists would initiate anticipatory guidance of firearm safety was assessed by a series of chisquare tests for gender, age, location of practice and firearm ownership of the psychologists and none were significant.

Approximately $57 \%$ of clinical psychologists reported counseling all or most of their suicidal patients regarding firearm safety. All other groups with mental health disorders were counseled about firearm safety by less than $50 \%$ of the respondents. The rates of anticipatory guidance on firearm safety varied by type of mental health disorder of the patient (Table 1).

Slightly more than one-third of clinical psychologists reported never (36.6\%) discussing the dangers of firearms with patients. Almost $40 \%$ reported never discussing the proper storage of firearms with their patients. While $37 \%$ never discussed with their patients the dangers of keeping loaded firearms in the home. In addition, $40 \%$ reported never discussing other means of personal protection with their patients. The clinical psychologists were requested to select all that apply from a list of 10 potential barriers. Almost half of the clinical psychologists reported one barrier to their firearm safety counseling and another quarter $(25.1 \%)$ reported two barriers. The most common barriers reported by the psychologists were: "The majority of my patients would not need discussion of firearm safety" (73\%); "patients do not request information of firearm safety" (35\%); and "lack of personal expertise" (22\%). All other potential barriers were supported by less than $20 \%$ of the psychologists.

\section{Efficacy Expectations of Using the 5As}

The clinical psychologists efficacy expectations in using the 5As in counseling their patients on firearm issues is listed in Table 2. The majority of clinical psychologists reported being confident in their ability to "ask patients about the presence of firearms in their home" (84\%), in "advising patients to remove firearms from the home" $(80 \%)$, and assessed the "willingness of patients to remove firearms from their homes within 30 days" (68.2\%). A series of chi-square tests for confidence in using the 5 As by gender, age, location of practice, and firearm ownership status found no significant differences.

\section{Outcome Expectations of Using the 5As}

The majority (58\%) of clinical psychologists believed it was likely that firearm safety counseling would reduce the number of suicide attempts and suicides in patients and/or

Table 1 Provision of anticipatory guidance on firearm safety for patients with selected mental health issues (percent)

\begin{tabular}{llllr}
\hline Mental health issue & All/most & Few/none & Not applicable \\
\hline Suicidal patients & 57.5 & 10.3 & 25.1 & 7.1 \\
Major depression & 28.9 & 25.1 & 39.2 & 6.8 \\
Bipolar disorder & 18.6 & 20.9 & 45.7 & 14.7 \\
Borderline personality disorder & 18 & 21.8 & 40.4 & 19.8 \\
Alcoholism/other substance abuse & 16.5 & 21.5 & 44.6 & 17.4 \\
PTSD & 14.7 & 20.4 & 48.4 & 16.5 \\
Schizophrenia & 10.9 & 11.5 & 38.4 & 39.2 \\
Panic disorder & 6.2 & 13.3 & 65.5 & 15 \\
Anxiety disorder & 5.6 & 15.6 & 64.9 & 13.6 \\
Social phobia & 5.3 & 8.6 & 67.3 & 18.9 \\
\hline
\end{tabular}

$n=339$

${ }^{\text {a }}$ All (100\%), most (99-51\%), some (50-26\%), few (25-1\%), none (0\%) 
Table 2 Efficacy expectations of clinical psychologists regarding use of 5As in firearm anticipatory guidance on firearm safety

\begin{tabular}{|c|c|c|c|c|c|c|}
\hline \multirow[t]{2}{*}{$5 A^{\prime}$ 's item } & \multicolumn{2}{|c|}{ Not confident } & \multicolumn{2}{|c|}{ Moderately confident } & \multicolumn{2}{|c|}{ Confident } \\
\hline & $N$ & $(\%)$ & $N$ & $(\%)$ & $N$ & $(\%)$ \\
\hline \multicolumn{7}{|l|}{ Efficacy expectations } \\
\hline Asking my patients about the presence of firearms in the home & 12 & $(3.5)$ & 41 & $(12.2)$ & 283 & $(84.2)$ \\
\hline Advising my patients to remove the firearm from the home & 26 & $(7.8)$ & 41 & $(12.2)$ & 268 & $(80)$ \\
\hline Arranging follow-up contact within 4 weeks to assess firearm removal & 71 & $(21.6)$ & 69 & $(21.0)$ & 188 & $(57.3)$ \\
\hline Assisting my patients in what to do with the firearm after home removal & 10 & (30.6) & 66 & $(19.8)$ & 165 & $(49.5)$ \\
\hline
\end{tabular}

$N=329-336$

Table 3 Outcome expectations of clinical psychologists regarding use of the 5As in anticipatory guidance on firearm safety

\begin{tabular}{|c|c|c|c|c|c|c|}
\hline \multirow[t]{2}{*}{$5 A^{\prime}$ s item } & \multicolumn{2}{|c|}{ Unlikely } & \multicolumn{2}{|c|}{ Not sure } & \multicolumn{2}{|c|}{ Likely } \\
\hline & $N$ & $(\%)$ & $N$ & $(\%)$ & $N$ & $(\%)$ \\
\hline \multicolumn{7}{|l|}{ Outcome expectations } \\
\hline Reduction in the number of firearm suicide attempts and suicides in patients and/or their families & 44 & $(13.0)$ & 95 & $(28.0)$ & 197 & $(58.1)$ \\
\hline Reduction in the number of accidental firearm injuries or deaths to patients and/or their families & 47 & $(13.9)$ & 105 & $(31.0)$ & 183 & $(54.0)$ \\
\hline Reduction in the number of firearm homicides in patients and/or their families & 60 & (17.7) & 132 & $(38.9)$ & 144 & $(42.5)$ \\
\hline Reduction in the number of patients' homes with firearms & 106 & $(31.3)$ & 113 & $(33.3)$ & 118 & (34.8) \\
\hline
\end{tabular}

$N=329-336$

their families. The majority (54\%) also believed that firearm safety counseling would reduce the number of accidental firearm injuries or deaths to patients (Table 3). A series of chi-square tests for perceived outcomes of anticipatory guidance on firearm safety found no significant differences by gender, age, location of practice, and firearm ownership.

\section{Sources of Firearm Safety Information}

The majority (54\%) of clinical psychologists reported they had received information on firearm safety issues. However, $20 \%$ of this group received their information from the mass media. Thirteen percent reported graduate training in firearm counseling. Professional journals played almost no role $(7 \%)$ in their professional education on this topic. A series of chi-square tests for sources of information regarding firearm safety issues by gender, age, location of practice, and firearm ownership found no significant differences.

\section{Discussion}

Over half of the clinical psychologists $(51.6 \%)$ reported they would initiate firearm safety counseling if their patients were assessed as at risk for self-harm or harm to others, which is higher than what physicians have reported. A variety of studies have explored the role of physicians in reducing firearm injuries and premature mortality [21, 22]. Thirty-eight percent of primary care physicians reported engaging in firearm safety counseling and $15.7 \%$ of pediatricians reported firearm safety counseling [41]. The reported level of initiating firearm safety counseling by the counselors was higher than reported by psychiatrists [28]. However, even though clinical psychologists are better at anticipatory guidance on firearm safety issues than many clinicians, they still have considerable room for improvement.

Patients who could have been characterized as higher risk for firearm violence did not affect the probability of them receiving firearm safety counseling. These high risk characteristics included gender (male), racial/ethnic minorities, and low socioeconomic status. This is disconcerting because males are at increased risk of suicide. Results of one study indicated that males were 3.5 times more likely to commit suicide than were females [42]. In addition, African Americans have been found to be six times more likely than Caucasians to be perpetrators or victims of homicide and is the group mostly likely to die from firearm trauma [43]. Homicides by firearm vary in states by the percent of the population that was African American after controlling for firearms prevalence, number of firearm dealers, presence of firearm laws, alcohol 
consumption, socioeconomic status, and violent crimes [44].

The majority (78\%) of clinical psychologists did not have a routine system for identifying patients with firearms. Yet, these professionals believed those with mental health issues were at increased risk from firearms. Thus, it seems logical that clinical psychologists should collect information on access to firearms as if they were collecting any other baseline information that could affect the well being of their patients. Firearm access needs to become a vital sign for patients with mental health problems.

Fewer than $10 \%$ of clinical psychologists reported discussing the dangers of firearms, proper storage, dangers of loaded firearms, or discussing other means of personal safety. Storing firearms locked and unloaded decreases the risk of suicide [8]. However, keeping a firearm in the home regardless of storage method increased the risk of suicide and homicide [9]. Thus, it is important that firearms not be an environmental risk factor for premature death for patients with mental health issues.

Almost three-fourths of clinical psychologists reported at least one barrier to firearm safety counseling. The most frequent barrier was "The majority of my patients would not need discussion on firearm safety" (72.9\%). A study of patient suicide found that $23 \%$ of counselors had a patient under their care commit suicide [32]. The second most identified barrier was "patients do not request information on firearm safety" (35.1\%). Family practice physicians reported lack of time, unsure what to tell patients, and patients would not take advice as barriers to anticipatory guidance [23]. While psychiatrists indicated "lack of time" "lack of personal expertise", and "patients not requesting information on firearm safety" as among their most common barriers [28]. These barriers seem incongruent with the problem considering $78.5 \%$ of clinical psychologists perceived firearm safety issues as greater among patients with mental health problems. Such a disconnect between the perceived importance and the lack of action may indicate inadequate preparation in professional training.

Schizophrenic patients have a risk of suicide almost 10 times that of the general population $(\mathrm{OR}=9.9)[18]$. Yet, one-quarter of clinical psychologists reported counseling none of their schizophrenic patients on firearm safety issues. Twenty-eight percent of clinical psychologists reported counseling all or most of their depressed patients. Eighteen percent of clinical psychologists reported firearm safety counseling among all or most of their bipolar patients. Depression, bipolar disorder and schizophrenia are associated with repeated suicide attempts and suicide ideation [16, 17]. Substance abuse disorders increase the risk of suicide among attempters $(\mathrm{OR}=2.28)$ [45]. Only $16.5 \%$ of clinical psychologists in the current study reported counseling all or most of their alcohol/substance abuse patients regarding firearm safety issues. Most suicides involve substance abuse prior to the attempt. These results imply a lack of adequate training and inadequate care being delivered by the majority of clinical psychologists for these disorders. The only disorder the majority $(57.5 \%)$ of clinical psychologists reported counseling all or most of their patients on regarding firearms was suicidal patients.

Only one-quarter $(26.3 \%)$ of clinical psychologists were highly confident in their ability to apply the 5A's of firearm safety counseling. Education and training needs to be offered to clinical psychologists regarding the dangers of firearms and how to properly assess patient risk. There were no statistically significant difference by sex, age, firearm control groups membership, location of practice, or race/ethnicity, which again imply a universal lack of adequate training. Most large medical organizations have policies on anticipatory guidance on firearm safety issues. These include the American Medical Association, American Psychiatric Association and the American Academy of Pediatrics [46]. It may be time for the American Psychological Association (APA) to follow suit and take a strong position on this important topic. Only $7.1 \%$ of clinical psychologists reported discussing firearm safety counseling with the majority of their patients.

Few $(12.1 \%)$ clinical psychologists reported receiving graduate level training in anticipatory guidance regarding firearm safety. Firearm safety counseling training should be incorporated in the graduate training of all clinical psychologists. Almost one-quarter $(22.7 \%)$ of clinical psychologists reported receiving training from the mass media, however, this is not a valid source of information for training professionals. The media does not provide specific information on anticipatory guidance regarding firearm safety. This demonstrates the need for measures towards educating clinical psychologists about firearm safety counseling, and for those educating and training clinical psychologists to make this a priority.

\section{Limitations}

There are several potential limitations to this study which need to be addressed. First, the study was based on a selfadministered questionnaire. As characteristic of all survey research, if some respondents answered some of the questions in a socially desirable way then the data may over or under represent clinical psychologists views. Second, this study had an adequate response rate (62\%), however, to the extent that the non-respondents might have answered the questions differently then this would limit the external validity of the findings. Third, the sample was from the APA and thus these findings may not apply to 
clinical psychologists who are not members of the APA. Finally, the questionnaire was monothematic (only covering firearm safety) which may have created a mindset in responding to the questions that may not have been indicative of the respondents true perceptions and practices.

Open Access This article is distributed under the terms of the Creative Commons Attribution Noncommercial License which permits any noncommercial use, distribution, and reproduction in any medium, provided the original author(s) and source are credited.

\section{References}

1. Centers for Disease Control and Prevention. (2005). Web-based injury statistics query and reporting system (WISQARS) [online]. Available from: www.cdc.gov/ncipc/wisquars. (Cited 1 April 2006).

2. Romero, M. P., \& Wintemute, G. J. (2002). The epidemiology of firearm suicide in the United States. Journal of Urban Health: Bulletin of the New York Academy of Medicine., 79(1), 39-48.

3. Hoyert, D. L., Kung, H. C., \& Smith, B. L. (2005). Deaths: Preliminary data for 2003. National Vital Statistics Report, 53(15), 1-48.

4. Grassel, K. M., Wintemute, G. J., Wright, M. A., \& Romero, M. P. (2003). Association between handgun purchase and mortality from firearm injury. Injury Prevention, 9, 48-52. Accessed on 21 May 2005 at: ip.bmjjournals.com.

5. Hemenway, D., \& Miller, M. (2002). Association of rates of household handgun ownership, lifetime major depression, and serious suicidal thoughts with rates of suicide across US census regions. Injury Prevention, 8, 313-316.

6. Miller, M., Azrael, D., \& Hemenway, D. (2002). Rates of household firearm ownership and homicide across US regions and states, 1988-1997. American Journal of Public Health, 92(12), 1993-1998.

7. National Center for Health Statistics. (2004). Deaths: final data for 2002. National Vital Statistics Report, 52(21).

8. Shenassa, E. D., Rogers, M. L., Splading, K. L., \& Roberts, M. B. (2004). Safer storage of firearms at home and risk of suicide: A study of protective factors in a nationally representative sample. Journal of Epidemiology and Community Health, 58, 841-848.

9. Dahlberg, L. L., Ikeda, R., \& Kresnow, M. (2004). Guns in the home and risk of a violent death in the home: Findings from a national survey. American Journal of Epidemiology, 160(10), 929-936.

10. Brent, D. A., Perper, J. A., Moritz, G., Baugher, M., Schweers, J., $\&$ Roth, C. (1994). Suicide in affectively ill adolescents: A casecontrol study. Journal of Affective Disorders, 31, 193-202.

11. Dhossche, D. M., Meloukheia, A. M., \& Chakravorty, S. (2000). The association of suicide attempts and comorbid depression and substance abuse in psychiatric consultation patients. General Hospital Psychiatry, 22, 281-288.

12. Goodwin, F. K., Fireman, B., Simon, G. E., Hunkeler, E. M., Lee, J., \& Revicki, D. (2003). Suicide risk in bipolar disorder during treatment with lithium and divalproex. Journal of the American Medical Association, 290(11), 1467-1473.

13. Lester, D. (1998). Preventing suicide by restricting access to methods for suicide. Archives of Suicide Research, 4, 7-24.

14. Miller, M., \& Hemenway, D. (1999). The relationship between firearms and suicide: A review of the literature. Aggression and Violent Behavior, 4(1), 59-75.
15. Shah, S., Hoffman, R. E., Wake, L., \& Marine, W. M. (2000). Adolescent suicide and household access to firearms in Colorado: Results of a case-control study. Journal of Adolescent Health, 26(3), 157-163.

16. Funahashi, T., Ibuki, Y., Domon, Y., Nishimura, T., Akehashi, D., \& Sugiura, H. (2000). A clinical study on suicide among schizophrenics. Psychiatry and Clinical Neurosciences, 54, 173179.

17. Spirito, A., Veleri, S., Boergers, J., \& Donalsdon, D. (2003). Predictors of continued suicidal behavior in adolescents following a suicide attempt. Journal of Clinical Child and Adolescent Psychology, 32(2), 284-289.

18. Heila, H., Haukka, J., Suvisaari, J., \& Lonnqvist, J. (2005). Mortality among patients with schizophrenia and reduced psychiatric hospital care. Psychological Medicine, 35, 725-732.

19. Hiroeh, U., Appleby, L., Mortensen, P. B., \& Dunn, G. (2001). Death by homicide, suicide, and other unnatural causes in people with mental illness: A population-based study. Lancet, 358, 2110-2112.

20. Kung, H. C., Pearson, J. L., \& Liu, X. (2003). Risk factors for male and female suicide decedents ages 15-64 in the United States: Results from the 1993 National Mortality Followback Survey. Social Psychiatry and Psychiatric Epidemiology, 38, 419-426.

21. Grossman, D. C., Mang, K., \& Rivara, F. P. (1995). Firearm injury prevention counseling by pediatricians and family physicians: Practices and beliefs. Archives of Pediatric and Adolescent Medicine, 149, 973-977.

22. Price, J. H., Conley, P. M., \& Oden, L. (1997). Training in firearm safety counseling in pediatric residency programs. Archives of Pediatric and Adolescent Medicine, 151, 306-310.

23. Everett, S. A., Price, J. H., Bedell, A. W., \& Telljohann, S. K. (1997). Family practice physicians' firearm safety counseling beliefs and behaviors. Journal of Community Health, 22(5), 313324.

24. Fargason, C. A., \& Johnston, C. (1995). Gun ownership and counseling of Alabama pediatricians. Archives of Pediatrics and Adolescent Medicine, 149, 442-446.

25. Price, J. H., Everett, S. A., Bedell, A. W., \& Telljohann, S. K. (1997). Reduction of firearm-related violence through firearm safety counseling. Archives of Family Medicine, 6, 79-83.

26. Price, J. H., Clause, M., \& Everett, S. A. (1995). Patients' perceptions of the role of the physician in counseling about firearms. Patient Education and Counseling, 25, 163-170.

27. Wright, M. S. (1997). Pediatric injury prevention: Preparing residents for patient counseling. Archives of Pediatrics and Adolescent Medicine, 151, 1039-1043.

28. Price, J., Kinnison, A., Dake, J., Thompson, A., \& Price, J. (2007). Psychiatrists' practices and perceptions regarding anticipatory guidance on firearms. American Journal of Preventive Medicine, 33(5), 370-373.

29. Bongar, B. M. (2002). The suicidal patient: Clinical and legal standards of care. Washington, DC: American Psychological Association.

30. International Association for Suicide Prevention. (2000). IASP guidelines for suicide prevention. International Assciation for Suicide Prevention. Available [on-line] at: http://www.med.uio. no/iasp/english/guidelines.html.

31. Carney, C. P., Allen, J., \& Doebbeling, B. N. (2002). Receipt of clinical preventive medical services among psychiatric patients. Psychiatric Services, 53(8), 1028-1030.

32. McAdams, C. R., \& Foster, V. A. (2000). Client suicide: It's frequency and impact on counselors. Journal of Mental Health Counseling, 22(2), 107-121.

33. Mann, J. J., Apter, A., Bertolote, J., Beautrais, A., Currier, D., Haas, A., et al. (2005). Suicide prevention strategies: A 
systematic review. Journal of the American Medical Association, 294(16), 2064-2074.

34. Sherman, M. E., Burns, K., Ignelzi, J., Rain, J., Lofton, V., Toland, D., et al. (2001). Firearms risk management in psychiatric care. Psychiatric Services, 52(8), 1057-1061.

35. Price, J. H., Dake, J. A., Murnan, J., Dimmig, J., \& Akpanudo, S. (2005). Power analysis in survey research: Importance and use for health educators. American Journal of Health Education, 36(4), 202-207.

36. Bandura, A. (1997). Self-efficacy: Toward a unifying theory of behavior change. Psychology Review, 84, 191-215.

37. Bentz, C., Bayley, K. B., Bonin, K., Fleming, L., Hollis, J., Hunt, J. S., et al. (2007). Provider feedback to improve 5 A's tobacco cessation in primary care: A cluster randomized clinical trial. Nicotine \& Tobacco Research, 9, 341-349.

38. Edwards, P., Roberts, I., Clarke, M., Diguiseppi, C., Pratap, S., Wentz, R., et al. (2002). Increasing response rates to postal questionnaire: Systematic review. British Medical Journal, 324, 1183-1191.

39. Dillman, D. A. (2000). Mail and internet surveys: The tailored design method. New York: Wiley \& Sons.

40. King, K. A., Pealer, L. N., \& Bernard, A. L. (2001). Increasing response rates to mail questionnaires: A review of the inducement strategies. American Journal of Health Education, 32, 4-15.
41. Barkin, S., Duan, N., Fink, A., Brook, R. H., \& Gelberg, L. (1998). The smoking gun: Do clinicians follow guidelines on firearm safety counseling? Archives of Pediatrics and Adolescent Medicine, 152, 749-755.

42. Agerbo, E., Nordentoft, M., \& Mortensen, P. B. (2002). Familial, psychiatric, and socioeconomic risk factors for suicide in young people: nested case-control study. British Medical Journal, 325, 74-79.

43. Fox, J. A., \& Zawitz, M. W. (2004). Homicide trends in the United States: 2002 Update. United States Department of Justice: Bureau of Justice Statistics. NCJ 204885.

44. Price, J. H., Thompson, A. J., \& Dake, J. (2004). Factors associated with state variations in homicide, suicide, and unintentional firearm deaths. Journal of Community Health, 29, 271-283.

45. Suominen, K., Isometsa, E., Haukka, J., \& Lonnqvist, J. (2004). Substance use and male gender as risk factors for death and suicide: A 5-year follow-up study after deliberate self-harm. Social Psychiatry and Psychiatric Epidemiology, 39, 720-724.

46. Longjohn, M. M., \& Christoffel, K. K. (2004). Are medical societies developing a standard for gun injury prevention? Injury Prevention, 10, 169-173. 